\title{
Role of cartilage-forming cells in regenerative medicine for cartilage repair
}

REVIEW

This article was published in the following Dove Press journal:

Orthopedic Research and Reviews

22 September 2010

Number of times this article has been viewed

\section{Lin Sun'}

\section{Michaela R Reagan ${ }^{2}$}

David L Kaplan ${ }^{1,2}$

'Department of Chemical and Biological Engineering, ${ }^{2}$ Department of Biomedical Engineering, Tufts University, Medford, MA, USA
Correspondence: David L Kaplan Department of Biomedical Engineering, Tufts University, 4 Colby St, Medford, MA, USA

Tel + I 617627325 I

Fax + I 6176273231

Email david.kaplan@tufts.edu
Abstract: Currently, cartilage repair remains a major challenge for researchers and physicians due to its limited healing capacity. Cartilage regeneration requires suitable cells; these must be easily obtained and expanded, able to produce hyaline matrix with proper mechanical properties, and demonstrate sustained integration with native tissue. At present, there is a wide variety of possible cell sources for cartilage regeneration. This review explores the diversity of sources for cartilage-forming cells and the distinctive characteristics, advantages, limitations, and potential applications of each cell source. We place emphasis on cell sources used for in vitro and clinical studies.

Keywords: cell sources, cartilage regeneration, stem cells, chondrocytes

\section{Introduction}

Due to its avascular structure, cartilage tissue has limited innate regenerative ability. In 1743, William Hunter described "ulcerating cartilage" by explaining "From Hippocrates to the present age... when cartilage is destroyed, it is never recovered". Since then, various techniques including debridement and lavage, marrow stimulation, autologous chondrocyte implantation (ACI), the osteochondral autograft transfer system (OATS), tissue engineering, and other techniques have been explored to improve cartilage regeneration, some of which have found their way to the clinic. ${ }^{2,3}$ However, till date, no technique has reliably regenerated the biological composition and biomechanical properties of native cartilage, leaving unresolved pain and loss of joint function for millions of patients with defective cartilage from aging, injury, or disease.

In general, surgical intervention for cartilage lesions can be divided into marrow-stimulating (reparative) techniques and reconstructive techniques. Abrasion chondroplasty, Pridie drilling, and microfracture are reparative surgical techniques for bone marrow stimulation, which may stimulate healing by breaking bone around the defect but can result in the production of an inferior quality of newly formed fibrocartilage tissue. ${ }^{3}$ Reconstructive techniques include ACI, characterized chondrocyte implantation (CCI), and other variations of tissue engineering. ${ }^{4} \mathrm{ACI}$ and $\mathrm{CCI}$ involve the removal of healthy chondrocytes from a patient and the implantation of these into a defective cartilage site, stimulating the growth of new hyaline cartilage while avoiding graft rejection. However, the drawbacks of ACI and CCI include limited cell sources, difficulty in phenotype retention, and donor-site morbidity, all of which challenge autologous cell transfer procedures. ${ }^{5,6}$ Thus, new strategies rely upon cell therapies that explore the use of stem cells rather than primary chondrocytes for cartilage regeneration. Since 
the range of potential cell sources for cartilage regeneration is so extensive, the following criteria may help identify the best candidate cell sources for cartilage regeneration: 1) easy to isolate and collect, 2) easy to expand in vitro to yield a large number of cells, 3) capable of expressing and synthesizing cartilage-specific molecules, 4) capable of producing neocartilage with comparable mechanical properties to native cartilage, 5) capable of integrating into the surrounding recipient site, and 6) immunocompatible. ${ }^{2,7,8}$ With regard to these design goals, we have reviewed the cell sources used for cartilage lesion treatment and the trajectory of the field. We have compared potential cell sources, discussed their function in cartilage regeneration, and assessed their success in in vitro models and clinical experiences.

\section{Chondrocyte cell sources}

Cartilage mainly consists of avascular extracellular matrix (ECM) and has a low density of cartilage matrix-depositing cells namely chondrocytes. Mature chondrocytes are characterized by a round morphology and are located in lacuna structures. These cells are logical candidates for cartilage repair because they produce type II collagen, sulfated glycosaminoglycans (GAGs), and other ECM molecules that constitute functional cartilage. ${ }^{9}$ Chondrocytes are mainly isolated from articular cartilage for reparative procedures, but they can also be isolated from other cartilage structures (ie, nasal, auricle, and costal cartilage), as discussed below.

\section{Articular cartilage chondrocytes}

Mature articular cartilage is an anisotropic tissue organized into superficial, middle, and deep zones, and changes with depth reflect the tensile and compressive forces acting on the tissue. The superficial zone is at the articular surface, whereas the deep zone adjoins the calcified cartilage, which integrates into the subchondral bone. Chondrocytes from different zones have unique gene expression profiles of zonal markers (ie, proteoglycan (PG)-4, collagen type $\mathrm{X}$, and clusterin) and matrix protein expression levels. ${ }^{5,10,11}$ Chondrocytes from the deep zone are able to proliferate faster, produce more total ECM, and produce ECM with a greater ratio of GAGs to collagen than chondrocytes from the middle or superficial zones. Interestingly, engineered cartilage tissues grown in vitro from chondrocytes show different zonal properties corresponding to the zone from which the cells were isolated. ${ }^{12}$ In a study by Waldman et al, ${ }^{12}$ a mixture of full-thickness chondrocytes isolated from all zones demonstrated the highest collagen synthesis after being seeded and cultured in calcium phosphate substrates for 8 weeks, compared with more homogenous deep zone only chondrocytes or middle zone only chondrocytes. The combination of middle zone and deep zone chondrocytes showed the highest accumulation of aggrecan and superior mechanical properties. However, culture conditions and cell-cell communication affect the retention of zonal-specific characteristics; all 3 zones of equine chondrocytes can restore their zonal matrix expression in alginate culture, but not in pellet culture. ${ }^{13}$

Articular chondrocytes have proven successful in surgical operations such as OATS or ACI. OATS is a procedure where an osteochondral plug of hyaline cartilage and bone is taken from a non-load-bearing area and packed into a prepared cavity. Mosaicplasty is similar but involves the use of multiple smaller plugs and the filling of smaller holes in the defect, which can produce a mosaic histological result. Although OATS and mosaicplasty can provide favorable results, complications have been reported including osteochondral plug fracture, postoperative hematoma, surface incongruity, donor-site morbidity, and insufficient stability of the graft. ${ }^{14}$ Thus, although articular chondrocytes within osteochondral plugs, can enhance cartilage healing, the donor-site morbidity associated with removing large sections of bone and cartilage suggests that the use of articular chondrocytes alone, in a regenerative process, may serve the patient better. ${ }^{15}$ The most common articular chondrocyte-based surgical procedure is ACI, which has demonstrated improved results compared with OATS. ${ }^{16}$

ACI was first applied to a knee cartilage defect in 1994 and since then, it has been widely studied in the field of cartilage repair. ${ }^{9}$ In the ACI process, autologous articular chondrocytes are collected from a low-load-bearing area of a joint, expanded in vitro, resuspended, injected into a defect, and covered by a periosteal flap or collagen membrane. Generally, improved healing responses are reported with ACI treatment; neocartilage-like tissue is often formed, and defects are filled more completely with chondrocyte treatment than when left untreated or treated with cell-free therapies. Although the newly formed tissue is mainly fibrocartilaginous, some long-term follow-up studies suggest that the clinical functionality of ACI remains high even 10-20 years after the implantation. ${ }^{17,18}$

However, other studies have found the benefit of ACI more questionable. A randomized trial of 80 patients found no histological or clinical difference between microfracture and ACI treatment groups at 2 years after surgery, and the microfracture group showed better results according to a short form (SF)-36 physical component score. ${ }^{19}$ A 5-year follow-up of the study reported the same findings. ${ }^{20} \mathrm{~A}$ more comprehensive review of 9 trials with 626 patients found no advantage of ACI over 
other treatments. ${ }^{21}$ Hence, till date, there is no sufficient existing randomized trial to prove the superiority of $\mathrm{ACI}$ to other treatment strategies for full-thickness cartilage defects. This may be due to the fact that all articular chondrocytes, rather than exclusively those able to regenerate cartilage, are used in ACI, an issue which is addressed in CCI.

In a step toward more precisely selecting cells able to regenerate lost cartilage, CCI was investigated in 2007 in a trial with 118 patients presenting with symptomatic cartilage defects of the knee..$^{22}$ Across 13 orthopedic centers, articular chondrocytes were harvested from patients and cultured in vitro, similar to ACI. However, before implantation, cells were sorted using flow cytometry based on specific markers that predict a population more capable of producing hyaline-like cartilage, and the selected cells were used for implantation. One year after treatment, CCI resulted in superior structural regeneration compared with microfracture, although no significant clinical differences were found when measured by the Knee injury and Osteoarthritis Outcome Score (KOOS). The results at 36 months showed that for the treatment of articular cartilage defects of the femoral condyles of the knee, CCI resulted in a significantly better clinical outcome compared with microfracture based on the KOOS. ${ }^{23}$ TiGenix (Leuven, Belgium) has further developed the technique of isolating a subpopulation of chondrocytes superior at hyaline production and formulated the product ChondroCelect. The latest 5-year follow-up results of the cell-based product in a clinical study confirmed the durability of the product and demonstrated improvements over microfracture after 1 and 3 years. ${ }^{24}$ However, as with ACI, the morbidity caused by the 2-stage procedure remains unresolved in CCI. ${ }^{3}$ Out of the many surgical techniques for cartilage repair and regeneration, those that hold the greatest promise are cellbased procedures, and articular chondrocytes have proven to be one successful cell source in ACI and CCI.

\section{Nasal and auricular cartilage chondrocytes}

In addition to articular chondrocytes, auricular (ear), nasal septum (nose), and costal (rib) chondrocytes can be isolated and used for cartilaginous tissue regeneration. Chondrocytes from different anatomical sites have different gene expression profiles, proliferative rates, and redifferentiation characteristics. Clinical studies have demonstrated that the 3 cell sources mentioned above can be used for autologous cartilage graft generation with auricular and nasal chondrocytes showing superior postexpansion chondrogenic potential. ${ }^{25-27}$ Many studies have demonstrated that both auricular and nasoseptal chondrocytes display higher cell yield and offer greater expansion opportunities when compared with articular chondrocytes. When cultured in alginate beads, auricular chondrocyte proliferation rates are up to 4 times that of articular chondrocytes. ${ }^{28}$ Kafienah et a ${ }^{29}$ found that human adult nasal chondrocytes proliferated approximately 4 times faster in monolayer culture and had greater chondrogenic capacity than human articular chondrocytes, but these chondrocytes may not survive or produce the same results in an articulating joint in vivo. Nasal chondrocytes can also be cultured at a very low density such that an 838-fold expansion can be reached within one passage without differentiation..$^{30}$ In addition, removal of auricular and nasal chondrocytes is much less invasive than removal of cartilage from a joint and causes fewer functional defects for the patient. Hence, nasal and auricular sites appear to be superior for cartilage removal and hold potential as a source for highly proliferative chondrocytes.

In vivo animal studies demonstrate that, when implanted in radically polymerized hyaluronic acid (HA) hydrogels, auricular chondrocytes cause construct growth, neocartilage formation, and an increase in aggregate modulus and ECM accumulation, whereas articular cartilage chondrocytes do not result in construct growth and produce a minimal increase in the compressive modulus. However, in vitro, contradictory differences in gene expression after dynamic mechanical loading were found. ${ }^{31}$ Since non-articular chondrocytes are not under mechanical loading in the natural state, they logically respond differently to mechanical loading compared with constantly loaded articular chondrocytes. This raises questions regarding the ability of nasal and auricular chondrocytes to withstand the mechanical forces experienced in the joint. It is also unclear how articular and non-articular chondrocytes will integrate into the surrounding tissue when implanted into a joint. ${ }^{7}$

\section{Allogeneic chondrocytes}

Although our understanding of the immune response to foreign cartilage and chondrocytes is limited, allogeneic chondrocytes may provide a solution to the low quantity of autologous chondrocytes typically obtained in ACI surgery and the associated donor-site morbidity. Large animal studies indicate that allogeneic chondrocytes from articular, auricular, and costal cartilage can support and encourage successful healing of lesions in the avascular zone of the meniscus. ${ }^{32}$ An in vitro study demonstrated the utility of harvesting chondrocytes from younger patients, where it was found that allogeneic chondrocytes from juvenile donors had greater potential to restore articular cartilage compared with chondrocytes from adult donors. ${ }^{33}$ Further, juvenile chondrocytes stimulated no 
immunologic response based on a lymphocyte proliferation assay, which may be due to the lack of their surface molecules that induce a T-cell immune response.$^{34}$ In another study, allogeneic human chondrocytes in alginate beads were implanted into 21 patients for the treatment of symptomatic cartilage defects in the knee, and a significant clinical improvement in patients was found after 6 and 24 months of follow-up. ${ }^{35}$ However, in this study, since the chondrocytes were encapsulated in an alginate gel, the alginate may have acted as an immune barrier and protected the chondrocytes from the immune system. ${ }^{36}$ Thus, the immune response to allogeneic chondrocytes remains to be investigated, although an immune barrier system may be considered as a potential strategy to overcome immune reactions.

\section{Stem cell sources}

\section{Mesenchymal stem cells}

Mesenchymal stem cells (MSCs) are pluripotent stromal cells resident in mesenchymal tissues that can be isolated using glass or tissue culture plastic adhesion, expanded in vitro, and differentiated into many lineages (osteogenic, adipogenic, and chondrogenic).$^{37}$ Although there is no single MSC marker, and the expression of MSC markers varies depending on donor, passage number, and source tissue type, MSCs are often characterized by the following surface marker profile: $\mathrm{CD}^{+} 3^{+}$, $\mathrm{CD}^{+}{ }^{+}, \mathrm{CD} 105^{+}, \mathrm{CD}_{166^{+}}, \mathrm{CD} 34^{-}$, and CD45- ${ }^{-}$However, even these markers are not always sufficient to identify MSCs, nor are their morphology able to specifically identify them. ${ }^{38}$ In contrast to primary chondrocytes, primary MSCs are isolated from different tissues and are more abundant within certain tissues, making them easier to isolate. Bone marrow-derived stem cells (BMSCs), adipose-derived stem cells (ADSCs), synovium-derived progenitor cells, and stem cells from skeletal muscle and umbilical cord blood are all capable of chondrogenic differentiation in appropriate culture environments. The ability for MSCs to differentiate down bone, cartilage, tendon and ligament lineages suggests the possibility of constructing a biphasic osteochondral graft, or even a more complex joint tissue from a single cell source or type. ${ }^{37}$

Limitations and potential risks in applying MSCs to cartilage repair remain. Expression of type X collagen, a major hypertrophy marker that can lead to calcification and vascularization, was found in BMSCs, ADSCs, and periosteum-derived progenitor cells (PDPCs) during chondrogenesis, whereas articular chondrocytes resist calcification. ${ }^{39,40}$ However, it is likely that hypertrophy can be prevented by improving differentiation parameters. For example, a recent study suggested that hypoxia may inhibit the expression of type $\mathrm{X}$ collagen during chondrogenesis of ADSCs. ${ }^{41}$ Another concern regarding MSCs is that BMSC-generated matrix is mechanically inferior to that generated by articular chondrocytes, perhaps because the in vitro differentiation of MSCs does not perfectly mimic normal chondrogenic differentiation in the body. ${ }^{42-44}$

\section{Bone marrow-derived stem cells}

BMSCs are one of the most common human adult MSCs used in tissue engineering and have been well studied for their ability to form cartilage-like structures in vitro and stimulate cartilage repair in animal models. Surgical techniques utilizing BMSCs include Pridie drilling and microfracture. With these procedures, the repair of fibrocartilage by bone stimulation is done by drilling small holes (a few $\mathrm{mm}$ for Pridie drilling or $0.5-1.0 \mathrm{~mm}$ for microfracture) into the subchondral bone plate after surgical debridement of cartilage defects. These are some of the most frequently used techniques for treating lesions of the articular cartilage in the knee, which work by stimulating bone marrow and encouraging marrow progenitor cells to migrate to the lesion. BMSCs, growth factors, and cytokines are released into the defect and penetrate into subchondral bone and articular cartilage where progenitor cells can differentiate into chondrocytes to begin to form new fibrocartilage or hyaline-like cartilage. ${ }^{45}$ These methods have proven safe and effective in many studies of articular knee cartilage defects, and microfracture was successful in the treatment of full-thickness chondral lesions of the knee in National Football League players. ${ }^{46,47}$ However, a recent report from Vasiliadis et $\mathrm{al}^{21}$ pointed out that microfracture provides good results in the short term (1-2 years), whereas ACI provides delayed but prolonged healing. Dozin et $\mathrm{al}^{48}$ compared the performance of ACI and mosaicplasty at resurfacing local full-thickness chondral defect of the knees of 47 patients and found that ACI and mosaicplasty were clinically equivalent, perhaps due to the trauma caused by mosaicplasty despite the mobilization of BMSCs. Moreover, bone marrow stimulation often generates fibrocartilage tissue of an inferior quality with less type II collagen and little resemblance to surrounding tissue. ${ }^{49}$ In addition, clinical results of drilling procedures and ACI are age dependent. This may be due to the general decrease in MSC populations in older patients, a decrease in older patients' healing potential, or the decreased ability of aged chondrocytes to produce collagen-rich, mechanically functional cartilage ECM, as demonstrated using aged bovine chondrocytes. $^{20,50,51}$ Clinical findings also demonstrate that patient's compliance is essential for healing in all mentioned procedures, and excessive activity too soon after surgery can cause great harm to the joint. ${ }^{52,53}$ Since many studies have 
found surgical fracture techniques unsuccessful at restoring normal hyaline cartilage and ineffectual in the long term, scientists have begun to explore more regenerative, stem cell-based tissue engineering options. ${ }^{54}$

BMSCs have been cultured in a variety of $3 \mathrm{D}$ systems in an effort to generate cartilage-like tissue, including collagen, ${ }^{55,56}$ gelatin, ${ }^{57}$ silk,${ }^{58}$ alginate,${ }^{59}$ hyaluronan, ${ }^{60}$ chitosan, ${ }^{61}$ agarose,${ }^{62}$ polyethylene glycol (PEG), ${ }^{63}$ polyglycolide (PGA), ${ }^{64}$ poly(lactic-co-glycolic acid), and hybrids of synthesized or natural materials. ${ }^{65-67}$ In general, regardless of scaffold structure, cartilage-like tissue can be induced using BMSCs, as evidenced by type II collagen and aggrecan expression and accumulation both in vivo and in vitro, and some studies have documented that chondrogenic differentiation and matrix deposition are superior in BMSCs compared with chondrocytes. ${ }^{68}$ Addition of growth factors like transforming growth factor $\beta 1$ (TGF $\beta 1$ ) and TGF $\beta 3$ can enhance chondrogenesis. ${ }^{69,70}$

Till date, only a handful of clinical studies using BMSCs have been published for cartilage applications. A series of clinical ACI studies were conducted where culture-expanded BMSCs were embedded in collagen gels and transplanted into cartilage defects covered with periosteum. ${ }^{71-75}$ In 2002, this system was tested on patients with knee osteoarthritis who underwent a high tibial osteotomy. A total of 12 of 24 patients were treated with BMSCs in an articular cartilage defect in the medial femoral condyle, whereas the other 12 subjects served as cell-free controls. The results showed that after 42 weeks, arthroscopic and histological grading scores were better in the cell-transplanted group than in the cell-free control group, but no significant clinical improvement was found. ${ }^{75}$ With this same system, 2 further studies were conducted in 2004 and 2007 on the repair of full-thickness articular cartilage defects in the patella and patellofemoral joints. Both studies found that defects were repaired with fibrocartilage at the study end points (1or 2 years after transplantation), although the patient's clinical symptoms improved after only 6 months. ${ }^{73,74}$ In 2010, a long-term follow-up was reported on BMSC transplantation for cartilage repair in 45 joints of 41 patients. The clinical results indicated that up to 11 years and 5 months after autologous transplantation of BMSCs, neither partial infections nor tumors appeared in these patients, which demonstrated the safety of using autologous MSC transplantation in cartilage repair. However, no functional repair outcomes were discussed. ${ }^{72}$

\section{Adipose-derived stem cells}

The chondrogenic potential of ADSCs has been validated in vitro using a variety of culture systems, growth factors, and differentiation culture conditions. Maintained in chondrogenic medium, chondrocyte-associated genes (type II collagen and aggrecan) can be induced in ADSCs, and substantial aggrecan protein can be transcribed and secreted. Challenges remain in stimulating the expression and accumulation of type II collagen in scaffolds, ${ }^{76}$ despite the addition of TGF $\beta 1 .{ }^{77}$ Still, in vivo experiments have verified that ADSCs differentiated toward chondrogenesis can proliferate and form new cartilage after subcutaneous injection with fibrin glue. ${ }^{78}$ In an in vitro pellet culture, ADSCs also demonstrate higher potential for chondrogenic differentiation compared with human umbilical cord matrix cells. ${ }^{79}$

ADSCs resemble BMSCs in their phenotype and their ability to differentiate into several mesenchymal lineages including the chondrocyte lineage, but they differ from BMSCs regarding their source tissue. ${ }^{80}$ Both cell types are recognized as potential cell sources for cartilage repair, but ADSCs appear advantageous in a few ways. ADSCs can be obtained via less invasive methods from large volumes of waste tissue from common surgeries (abdominoplasties and lipoplasties) and have a yield similar to BMSCs per gram of source tissue. ${ }^{81}$ However, some investigations have revealed that ADSCs have inferior chondrogenic potential compared with BMSCs and that pellet cultures of ADSCs show much weaker chondrogenesis in both cell morphology and matrix production. ${ }^{76,82,83}$ Another study confirmed that under the same chondrogenesis culture condition, type II collagen and PGs were synthesized only by the growth factor-treated human BMSCs, but not by human ADSCs. ${ }^{84}$ This reduced potential for chondrogenic differentiation may be a result of the lack of TGF- $\beta$ receptor expression and reduced expression of mRNAs for bone morphogenetic proteins (BMPs) in ADSCs compared with BMSCs. ${ }^{85}$

In animal studies, conflicting results for cartilage repair by ADSCs are reported. With supporting matrices of fibrin glue or fibrous PGA/polylactic acid scaffolds, induced ADSCs can heal full-thickness cartilage defects and form a hyalinelike cartilage tissue. ${ }^{86,87}$ In contrast, other reports found that the presence of ADSCs had no significant effect on cartilage repair compared with unseeded polycaprolactone/F127 scaffolds in a rabbit model. ${ }^{88}$ Till date, no clinical studies on ADSCs in cartilage regeneration have been reported.

\section{Embryonic stem cells}

Similar to the adult stem cells mentioned above, embryonic stem cells (ESCs) comprise an appealing prospective cell source for regenerative medicine due to their extensive in vitro expansion capability and multilineage differentiation potential. ${ }^{89}$ However, ethical issues and the heterogeneous and 
uncontrolled differentiation of ESCs currently limit clinical applications. Still, the use of ESCs for cartilage regeneration is an active area of study. One recent study demonstrated the ability of ESCs to differentiate in response to paracrine signaling from mature chondrocytes. A layer of feeder-free human ESCs were cocultured with primary chondrocytes and, with no further addition of growth factors, developed into an $85 \%$ positive chondrogenic-committed ESC culture. When the differentiated ESCs were embedded in PEG-based hydrogels and implanted subcutaneously into mice, they formed pellets of robust cartilage-like tissue and maintained their phenotype and tissue quality for 24 weeks. ${ }^{90} \mathrm{MSC}$ s isolated from human ESCs (hESCd-MSCs) have also shown multilineage differentiation potential in vitro and have demonstrated an ability to form neocartilage in mice when expanded in chondrocyteconditioned medium and embedded in PEG-based hydrogels. Chondrocyte-conditioned medium expanded hESCd-MSC pellets were also found to contribute to the full repair of cartilage defects in a rat model, suggesting a new, simple, and efficient strategy of using ESCs in cartilage repair. ${ }^{91}$

Perhaps the most promising result for ESCs in cartilage repair is from a study where hESCs were differentiated into chondrocytes using the growth factors BMP7 and TGF $\beta 1$ for 4 weeks and embedded into HA-based hydrogel constructs. ${ }^{92}$ The constructs were then examined in a rat model for their ability to repair critical-sized osteochondral defects. A hyaline-like neocartilage layer resulted with surface regularity and complete integration with adjacent host cartilage, and no signs of teratoma formation were found by 12 weeks. More importantly, an orderly remodeling process was observed resulting in complete osteochondral regeneration over a 12 week period. ${ }^{92}$ Progress is being made in developing the use of ESCs as a cartilage repair cell source; however, the technology has yet to reach a practical level.

\section{Synovium-derived stem cells}

MSCs were first successfully isolated from synovial membrane tissue by de Bari et $\mathrm{al}^{93}$ in 2001 and since then, researchers have probed these cells for their possible utility in musculoskeletal therapies, particularly for cartilage regeneration. Synoviumderived MSCs possess chondrogenic superiority compared with other MSC types. ${ }^{4}$ In terms of biological similarity, 1 study on synovial joint development revealed that articular chondrocytes and synovial cells originate from the same progenitor cell pool, and synovium-derived cells have higher hyaluronan receptor (CD44) expression and uridine diphosphoglucose dehydrogenase levels, key chondrocyte markers, compared with expression in other MSC types. Moreover, in synovial chondromatosis tumors, pathological cartilage is formed in the synovial tissue, indicating the chondrogenesis potential of synovial cells. ${ }^{94,95}$ In vitro investigations have shown that cartilage pellets formed by synovial MSCs are significantly larger and heavier than those formed from BMSCs. ${ }^{96}$ Other investigators compared human MSCs derived from 5 different tissue sources, including bone marrow, adipose, synovium, periosteum, and muscle in terms of yield, expansion, and chondrogenesis potential in pellet culture. Synovium-derived cells were found to have rapid expansion ability and the greatest ability for chondrogenesis. ${ }^{97}$ In 1 in vivo study, MSCs isolated from bone marrow, synovium, adipose tissue, and muscle of adult rabbits were embedded in collagen gels and transplanted to full-thickness cartilage defects. Synovium- and bone marrow-derived cells demonstrated higher chondrogenic potential than adipose- and muscle-derived cells, and synovium-derived cells possessed the greatest proliferation ability in vivo. ${ }^{98}$ Numerous studies have been conducted on the effects of chondrogenic inducers, including TGF $\beta$ family members, BMP2, and BMP7, in the chondrogenesis of synovium-derived MSCs. The results remain inconclusive, since different culture systems and combinations of growth factors have led to contradictory findings. ${ }^{98-101}$

\section{Periosteum-derived progenitor cells}

Periosteum, as a whole tissue, satisfies the following three requirements of a tissue-engineered construct: it contains cells, a scaffold, and correct signaling factors for the target tissue, in this case, cartilage. Periosteum contains pluripotent MSCs (among other cell types), ${ }^{93}$ an ECM or "scaffold" to mechanically support the cells, and many chondrogenic growth factors. ${ }^{102}$ It is not surprising, therefore, that when tested as a patch in cartilage defect repair, periosteum tissue guided the organization of chondrocytes and facilitated tissue formation in ACI procedure. One study compared the chondrogenic response of primary bovine chondrocytes and whole periosteum rabbit explants when mixed in alginate gels and cultured with TGF $\beta 1$. The cell-alginate constructs lacked the cellular and matrix organization of native hyaline cartilage after 42 days of in vitro culture, posing a significant barrier to utility. However, the periosteum-alginate samples showed extensive development of cartilage-like tissue with $54 \% \pm 8 \%$ of the total explant area staining positive with safranin-O, a cartilage-specific stain. ${ }^{103}$ Further studies of this system demonstrated that addition of FGF2 to the culture can increase proliferation of cells within the periosteum, increasing overall chondrogenesis, and that TGF $\beta 1$ was necessary for chondrogenesis to occur. ${ }^{104}$ 
The periosteum contains a fibrous layer and a cambium layer; PDPCs with chondrogenesis potential are resident in the cambium layer and are currently being examined for their potential as a cell source for cartilage engineering. ${ }^{105,106}$ A combination of positive and negative surface markers can be used for PDPC isolation, and similar to MSCs, CD34 and $\mathrm{CD} 45$ are not expressed on PDPCs. ${ }^{107}$ After sorting for CD105, SH2, SH3, and SH4, sorted PDPCs maintained chondrogenic potential over 15 passages in vitro. PDPCs show spontaneous chondrogenic activity at early passage numbers from young donors, but their chondrogenic differentiation capacity diminishes with age and passage number due to a decrease in stem cell number. ${ }^{39,108}$ Regardless of age or passage, the phenotype of PDPCs is stable during cell expansion within 15 passages, and chondrogenesis remains inducible via stimulation with the growth factors TGF $\beta 1$ and TGF $\beta 3 .{ }^{108}$ The chondrogenic potential of PDPCs is similar to other MSCs in vitro and in vivo, but further cell sorting may be used to improve the chondrogenic potential of PDPCs. In animal studies, periosteum- and bone marrow-derived cells showed similar results of chondrogenic differentiation in the repair of large, full-thickness defects of articular cartilage in rabbits. ${ }^{71,109}$ However, other research revealed that PDPCs do not survive for long periods within the repair tissue, and results are highly variable in animal experiments. ${ }^{4,110}$

\section{Conclusion}

In many cases, surgical methods for articular cartilage repair are successful in stimulating regrowth of damaged cartilage. Unfortunately, in many cases, repair may not be possible, and regeneration may be the only method for healing a defect and providing the patient pain-free and full-range mobility. Regeneration appears most successful when cell-based therapies are used, especially when the appropriate cells, matrices, and chemical signals are combined. Identification of the correct cell source is a key aspect in cartilage regeneration, as the source must provide a large reservoir of cells that are easily isolated and have strong chondrogenic potential, even after expansion. Primary chondrocytes and stem cells have advantages and disadvantages regarding these requirements, leaving the most useful cell source still debatable. However, during cartilage regeneration, the role of cell sources can be modified by other factors, including the environment in which they are cultured, chemical and biological factors, matrices, and other surgical procedures. This suggests that rather than hunting for an ideal cell source, combinations of the above features should be explored to improve cartilage regeneration. More in-depth analyses of the combinatorial effects of tissue engineering variables are needed to develop more durable, immunocompatible, integrative tissue-engineered articular cartilage. Steps in this direction suggest stem cells or subpopulations of primary chondrocytes may be the best current cell sources for regenerative and tissue engineering applications.

\section{Disclosure}

The authors report no conflicts of interest in this work.

\section{References}

1. Hunter W. Of the structure and disease of articulating cartilages. 1743. Clin Orthop Relat Res. 1995;317:3-6.

2. Clair BL, Johnson AR, Howard T. Cartilage repair: current and emerging options in treatment. Foot Ankle Spec. 2009;2(4):179-188.

3. Ahmed TA, Hincke MT. Strategies for articular cartilage lesion repair and functional restoration. Tissue Eng Part B Rev. 2010;16(3):305-329.

4. Hunziker EB. Articular cartilage repair: basic science and clinical progress. A review of the current status and prospects. Osteoarthritis Cartilage. 2002;10(6):432-463.

5. Chung C, Burdick JA. Engineering cartilage tissue. Adv Drug Deliv Rev. 2008;60(2):243-262.

6. Schulze-Tanzil G. Activation and dedifferentiation of chondrocytes: implications in cartilage injury and repair. Ann Anat. 2009;191(4): 325-338.

7. van Osch GJ, Brittberg M, Dennis JE, et al. Cartilage repair: past and future lessons for regenerative medicine. J Cell Mol Med. 2009;13(5): 792-810.

8. Ehnert S, Glanemann M, Schmitt A, et al. The possible use of stem cells in regenerative medicine: dream or reality? Langenbecks Arch Surg. 2009;394(6):985-997.

9. Brittberg M, Lindahl A, Nilsson A, Ohlsson C, Isaksson O, Peterson L. Treatment of deep cartilage defects in the knee with autologous chondrocyte transplantation. N Engl J Med. 1994;331(14):889-895.

10. Darling EM, Hu JC, Athanasiou KA. Zonal and topographical differences in articular cartilage gene expression. J Orthop Res. 2004;22(6): $1182-1187$.

11. Malda J, ten Hoope W, Schuurman W, van Osch GJ, van Weeren PR, Dhert WJ. Localization of the potential zonal marker clusterin in native cartilage and in tissue-engineered constructs. Tissue Eng Part A. 2010;16(3):897-904.

12. Waldman SD, Grynpas MD, Pilliar RM, Kandel RA. The use of specific chondrocyte populations to modulate the properties of tissue-engineered cartilage. J Orthop Res. 2003;21(1):132-138.

13. Schuurman W, Gawlitta D, Klein TJ, et al. Zonal chondrocyte subpopulations reacquire zone-specific characteristics during in vitro redifferentiation. Am J Sports Med. 2009;37 Suppl 1:S97-S104.

14. Intracorp Medical Necessity Guidelines. Available from: http://www. careallies.com/pdf/ex45_osteochondral_autograft_transplant.pdf. Accessed 2010 Aug 3.

15. Articular Cartilage Damage and Repair. Chester Knee Clinic and Cartilage Repair Center. Available from: http://www.kneeclinic.info/ problems_articular_cartilage.php. Accessed 2010 Aug 13.

16. Bentley G, Biant LC, Carrington RW, et al. A prospective, randomised comparison of autologous chondrocyte implantation versus mosaicplasty for osteochondral defects in the knee. J Bone Joint Surg Br. 2003;85(2):223-230.

17. Vasiliadis H, Salanti G, Georgoulis A, Lindahl A, Peterson L. Assessment of clinical outcomes 10-20 years after autologous chondrocyte implantation. Osteoarthritis Cartilage. Epub 2010 May 5.

18. Peterson L, Vasiliadis HS, Brittberg M, Lindahl A. Autologous chondrocyte implantation: a long-term follow-up. Am J Sports Med. 2010;38(6):1117-1124. 
19. Knutsen G, Engebretsen L, Ludvigsen TC, et al. Autologous chondrocyte implantation compared with microfracture in the knee. A randomized trial. J Bone Joint Surg Am. 2004;86-A(3):455-464.

20. Knutsen G, Drogset JO, Engebretsen L, et al. A randomized trial comparing autologous chondrocyte implantation with microfracture. Findings at five years. J Bone Joint Surg Am. 2007;89(10):2105-2112.

21. Vasiliadis HS, Wasiak J, Salanti G. Autologous chondrocyte implantation for the treatment of cartilage lesions of the knee: a systematic review of randomized studies. Knee Surg Sports Traumatol Arthrosc. Epub 2010 Feb 2.

22. Saris DB, vanlauwe J, Victor J, et al. Characterized chondrocyte implantation results in better structural repair when treating symptomatic cartilage defects of the knee in a randomized controlled trial versus microfracture. Am J Sports Med. 2008;36(2):235-246.

23. Saris DB, Vanlauwe J, Victor J, et al. Treatment of symptomatic cartilage defects of the knee: characterized chondrocyte implantation results in better clinical outcome at 36 months in a randomized trial compared to microfracture. Am J Sports Med. 2009;37 Suppl 1:S10-S19.

24. Positive 5-year ChondroCelect follow-up results to be presented at ESSKA. Tigenix. http:/www.tigenix.com/en/objects/docs/newsroom/ press_releases/2010/100608_TiGenix_Press_Release_5_Year_CC_ Data_EN.pdf. Accessed 2010 Aug 3.

25. Tay AG, Farhadi J, Suetterlin R, Pierer G, Heberer M, Martin I. Cell yield, proliferation, and postexpansion differentiation capacity of human ear, nasal, and rib chondrocytes. Tissue Eng. 2004;10(5-6):762-770.

26. van Osch GJ, Mandl EW, Jahr H, Koevoet W, Nolst-Trenite G, Verhaar JA. Considerations on the use of ear chondrocytes as donor chondrocytes for cartilage tissue engineering. Biorheology. 2004;41(3-4):411-421.

27. Malicev E, Kregar-Velikonja N, Barlic A, Alibegovic A, Drobnic M. Comparison of articular and auricular cartilage as a cell source for the autologous chondrocyte implantation. J Orthop Res. 2009;27(7):943-948.

28. Panossian A, Ashiku S, Kirchhoff CH, Randolph MA, Yaremchuk MJ. Effects of cell concentration and growth period on articular and ear chondrocyte transplants for tissue engineering. Plast Reconstr Surg. 2001;108(2):392-402.

29. Kafienah W, Jakob M, Demarteau O, et al. Three-dimensional tissue engineering of hyaline cartilage: comparison of adult nasal and articular chondrocytes. Tissue Eng. 2002;8(5):817-826.

30. Hicks DL, Sage AB, Schumacher BL, Sah RL, Watson D. Growth and phenotype of low-density nasal septal chondrocyte monolayers. Otolaryngol Head Neck Surg. 2005;133(3):417-422.

31. Chung C, Erickson IE, Mauck RL, Burdick JA. Differential behavior of auricular and articular chondrocytes in hyaluronic acid hydrogels. Tissue Eng Part A. 2008;14(7):1121-1131.

32. Weinand C, Peretti GM, Adams SB Jr, Randolph MA, Savvidis E, Gill TJ. Healing potential of transplanted allogeneic chondrocytes of three different sources in lesions of the avascular zone of the meniscus: a pilot study. Arch Orthop Trauma Surg. 2006;126(9):599-605.

33. Adkisson HD, Martin JA, Amendola RL, et al. The potential of human allogeneic juvenile chondrocytes for restoration of articular cartilage. Am J Sports Med. Epub 2010 Apr 27.

34. Adkisson HD, Milliman C, Zhang X, Mauch K, Maziarz RT, Streeter PR. Immune evasion by neocartilage-derived chondrocytes: implications for biologic repair of joint articular cartilage. Stem Cell Res. 2010;4(1):57-68.

35. Almqvist KF, Dhollander AA, Verdonk PC, Forsyth R, Verdonk R, Verbruggen $\mathrm{G}$. Treatment of cartilage defects in the knee using alginate beads containing human mature allogenic chondrocytes. Am J Sports Med. 2009;37(10):1920-1929.

36. Zimmermann H, Zimmermann D, Reuss R, et al. Towards a medically approved technology for alginate-based microcapsules allowing long-term immunoisolated transplantation. J Mater Sci Mater Med. 2005;16(6):491-501.
37. Krampera M, Pizzolo G, Aprili G, Franchini M. Mesenchymal stem cells for bone, cartilage, tendon and skeletal muscle repair. Bone. 2006;39(4):678-683.

38. Anthony Atala RL, James Thomson, Robert Nerem. Principles of Regenerative Medicine. Burlington: Academic Press; 2008.

39. Jansen EJ, Emans PJ, Guldemond NA, et al. Human periosteum-derived cells from elderly patients as a source for cartilage tissue engineering? J Tissue Eng Regen Med. 2008;2(6):331-339.

40. Winter A, Breit S, Parsch D, et al. Cartilage-like gene expression in differentiated human stem cell spheroids: a comparison of bone marrowderived and adipose tissue-derived stromal cells. Arthritis Rheum. 2003; 48(2):418-429

41. Betre H, Ong SR, Guilak F, Chilkoti A, Fermor B, Setton LA. Chondrocytic differentiation of human adipose-derived adult stem cells in elastin-like polypeptide. Biomaterials. 2006;27(1):91-99.

42. Mauck RL, Yuan X, Tuan RS. Chondrogenic differentiation and functional maturation of bovine mesenchymal stem cells in long-term agarose culture. Osteoarthritis Cartilage. 2006;14(2):179-189.

43. Erickson IE, Huang AH, Chung C, Li RT, Burdick JA, Mauck RL. Differential maturation and structure-function relationships in mesenchymal stem cell- and chondrocyte-seeded hydrogels. Tissue Eng Part A. 2009; 15(5):1041-1052.

44. Huang AH, Stein A, Tuan RS, Mauck RL. Transient exposure to transforming growth factor beta 3 improves the mechanical properties of mesenchymal stem cell-laden cartilage constructs in a densitydependent manner. Tissue Eng Part A. 2009;15(11):3461-3472.

45. Bedi A, Feeley BT, Williams RJ III. Management of articular cartilage defects of the knee. J Bone Joint Surg Am. 2010;92(4):994-1009.

46. Steadman JR, Miller BS, Karas SG, Schlegel TF, Briggs KK, Hawkins RJ. The microfracture technique in the treatment of fullthickness chondral lesions of the knee in National Football League players. J Knee Surg. 2003;16(2):83-86.

47. Steadman JR, Briggs KK, Rodrigo JJ, Kocher MS, Gill TJ, Rodkey WG. Outcomes of microfracture for traumatic chondral defects of the knee: average 11-year follow-up. Arthroscopy. 2003;19(5): $477-484$.

48. Dozin B, Malpeli M, Cancedda R, et al. Comparative evaluation of autologous chondrocyte implantation and mosaicplasty: a multicentered randomized clinical trial. Clin J Sport Med. 2005;15(4):220-226

49. Bae DK, Yoon KH, Song SJ. Cartilage healing after microfracture in osteoarthritic knees. Arthroscopy. 2006;22(4):367-374.

50. Tran-Khanh N, Hoemann CD, McKee MD, Henderson JE, Buschmann MD. Aged bovine chondrocytes display a diminished capacity to produce a collagen-rich, mechanically functional cartilage extracellular matrix. J Orthop Res. 2005;23(6):1354-1362.

51. Childers JC Jr, Ellwood SC. Partial chondrectomy and subchondral bone drilling for chondromalacia. Clin Orthop Relat Res. 1979;144: 114-120.

52. Browne JE, Anderson AF, Arciero R, et al. Clinical outcome of autologous chondrocyte implantation at 5 years in US subjects. Clin Orthop Relat Res. 2005;436:237-245.

53. Yen YM, Cascio B, O'Brien L, Stalzer S, Millett PJ, Steadman JR. Treatment of osteoarthritis of the knee with microfracture and rehabilitation. Med Sci Sports Exerc. 2008;40(2):200-205.

54. Gudas R, Stankevicius E, Monastyreckiene E, Pranys D, Kalesinskas RJ. Osteochondral autologous transplantation versus microfracture for the treatment of articular cartilage defects in the knee joint in athletes. Knee Surg Sports Traumatol Arthrosc. 2006;14(9):834-842.

55. Vickers SM, Gotterbarm T, Spector M. Cross-linking affects cellular condensation and chondrogenesis in type II collagen-GAG scaffolds seeded with bone marrow-derived mesenchymal stem cells. J Orthop Res. 2010;28(9):1184-1192.

56. Zheng L, Fan HS, Sun J, et al. Chondrogenic differentiation of mesenchymal stem cells induced by collagen-based hydrogel: an in vivo study. J Biomed Mater Res A. 2010;93(2):783-792. 
57. Kessler MW, Grande DA. Tissue engineering and cartilage. Organogenesis. 2008;4(1):28-32.

58. Meinel L, Hofmann S, Karageorgiou V, et al. Engineering cartilage-like tissue using human mesenchymal stem cells and silk protein scaffolds. Biotechnol Bioeng. 2004;88(3):379-391.

59. Xu J, Wang W, Ludeman M, et al. Chondrogenic differentiation of human mesenchymal stem cells in three-dimensional alginate gels. Tissue Eng Part A. 2008;14(5):667-680.

60. Chung C, Burdick JA. Influence of three-dimensional hyaluronic acid microenvironments on mesenchymal stem cell chondrogenesis. Tissue Eng Part A. 2009;15(2):243-254.

61. Ragetly GR, Griffon DJ, Lee HB, Fredericks LP, Gordon-Evans W, Chung YS. Effect of chitosan scaffold microstructure on mesenchymal stem cell chondrogenesis. Acta Biomater. 2010;6(4):1430-1436.

62. Mauck RL, Soltz MA, Wang CC, et al. Functional tissue engineering of articular cartilage through dynamic loading of chondrocyte-seeded agarose gels. J Biomech Eng. 2000;122(3):252-260.

63. Park H, Guo X, Temenoff JS, et al. Effect of swelling ratio of injectable hydrogel composites on chondrogenic differentiation of encapsulated rabbit marrow mesenchymal stem cells in vitro. Biomacromolecules 2009;10(3):541-546.

64. Wang L, Tran I, Seshareddy K, Weiss ML, Detamore MS. A comparison of human bone marrow-derived mesenchymal stem cells and human umbilical cord-derived mesenchymal stromal cells for cartilage tissue engineering. Tissue Eng Part A. 2009;15(8):2259-2266.

65. Han Y, Wei Y, Wang S, Song Y. Cartilage regeneration using adiposederived stem cells and the controlled-released hybrid microspheres. Joint Bone Spine. 2009;77(1):27-31.

66. Chen G, Liu D, Tadokoro M, et al. Chondrogenic differentiation of human mesenchymal stem cells cultured in a cobweb-like biodegradable scaffold. Biochem Biophys Res Commun. 2004; 322(1):50-55.

67. Fan $\mathrm{H}, \mathrm{Hu} \mathrm{Y}$, Zhang C, et al. Cartilage regeneration using mesenchymal stem cells and a PLGA-gelatin/chondroitin/hyaluronate hybrid scaffold. Biomaterials. 2006;27(26):4573-4580.

68. Kopesky PW, Lee HY, vanderploeg EJ, et al. Adult equine bone marrow stromal cells produce a cartilage-like ECM mechanically superior to animal-matched adult chondrocytes. Matrix Biol 2010;29(5):427-438.

69. Re'em T, Tsur-Gang O, Cohen S. The effect of immobilized RGD peptide in macroporous alginate scaffolds on TGF-beta1-induced chondrogenesis of human mesenchymal stem cells. Biomaterials. 2010; 31(26):6746-6755.

70. Bouffi $\mathrm{C}$, Thomas $\mathrm{O}$, Bony $\mathrm{C}$, et al. The role of pharmacologically active microcarriers releasing TGF-beta3 in cartilage formation in vivo by mesenchymal stem cells. Biomaterials. 2010;31(25):6485-6493.

71. Wakitani S, Goto T, Pineda SJ, et al. Mesenchymal cell-based repair of large, full-thickness defects of articular cartilage. J Bone Joint Surg Am. 1994;76(4):579-592.

72. Wakitani S, Okabe T, Horibe S, et al. Safety of autologous bone marrowderived mesenchymal stem cell transplantation for cartilage repair in 41 patients with 45 joints followed for up to 11 years and 5 months. J Tissue Eng Regen Med. Epub 2010 Jul 5.

73. Wakitani S, Nawata M, Tensho K, Okabe T, Machida H, Ohgushi H. Repair of articular cartilage defects in the patello-femoral joint with autologous bone marrow mesenchymal cell transplantation: three case reports involving nine defects in five knees. J Tissue Eng Regen Med 2007;1(1):74-79.

74. Wakitani S, Mitsuoka T, Nakamura N, Toritsuka Y, Nakamura Y, Horibe S. Autologous bone marrow stromal cell transplantation for repair of full-thickness articular cartilage defects in human patellae: two case reports. Cell Transplant. 2004;13(5):595-600.

75. Wakitani S, Imoto K, Yamamoto T, Saito M, Murata N, Yoneda M. Human autologous culture expanded bone marrow mesenchymal cell transplantation for repair of cartilage defects in osteoarthritic knees. Osteoarthritis Cartilage. 2002;10(3):199-206.
76. Jakobsen RB, Shahdadfar A, Reinholt FP, Brinchmann JE. Chondrogenesis in a hyaluronic acid scaffold: comparison between chondrocytes and MSC from bone marrow and adipose tissue. Knee Surg Sports Traumatol Arthrosc. Epub 2009 Dec 18.

77. Mahmoudifar N, Doran PM. Chondrogenic differentiation of human adipose-derived stem cells in polyglycolic acid mesh scaffolds under dynamic culture conditions. Biomaterials. 2010;31(14): $3858-3867$.

78. Jung SN, Rhie JW, Kwon $\mathrm{H}$, et al. In vivo cartilage formation using chondrogenic-differentiated human adipose-derived mesenchymal stem cells mixed with fibrin glue. J Craniofac Surg. 2010;21(2):468-472.

79. Hildner F, Wolbank S, Redl H, van Griensven M, Peterbauer A. How chondrogenic are human umbilical cord matrix cells? A comparison to adipose-derived stem cells. J Tissue Eng Regen Med. 2009;4(3): 242-245.

80. Wagner W, Wein F, Seckinger A, et al. Comparative characteristics of mesenchymal stem cells from human bone marrow, adipose tissue, and umbilical cord blood. Exp Hematol. 2005;33(11):1402-1416.

81. de Ugarte DA, Morizono K, Elbarbary A, et al. Comparison of multilineage cells from human adipose tissue and bone marrow. Cells Tissues Organs. 2003;174(3):101-109.

82. Im GI, Shin YW, Lee KB. Do adipose tissue-derived mesenchymal stem cells have the same osteogenic and chondrogenic potential as bone marrow-derived cells? Osteoarthritis Cartilage. 2005; 13(10):845-853.

83. Liu TM, Martina M, Hutmacher DW, Hui JH, Lee EH, Lim B. Identification of common pathways mediating differentiation of bone marrow- and adipose tissue-derived human mesenchymal stem cells into three mesenchymal lineages. Stem Cells. 2007;25(3):750-760.

84. Afizah H, Yang Z, Hui JH, Ouyang HW, Lee EH. A comparison between the chondrogenic potential of human bone marrow stem cells (BMSCs) and adipose-derived stem cells (ADSCs) taken from the same donors. Tissue Eng. 2007;13(4):659-666.

85. Hennig T, Lorenz H, Thiel A, et al. Reduced chondrogenic potential of adipose tissue derived stromal cells correlates with an altered TGF beta receptor and BMP profile and is overcome by BMP-6. J Cell Physiol. 2007;211(3):682-691.

86. Dragoo JL, Carlson G, McCormick F, et al. Healing full-thickness cartilage defects using adipose-derived stem cells. Tissue Eng. 2007;13(7): $1615-1621$.

87. Cui L, Wu Y, Cen L, et al. Repair of articular cartilage defect in nonweight bearing areas using adipose derived stem cells loaded polyglycolic acid mesh. Biomaterials. 2009;30(14):2683-2693.

88. Im GI, Lee JH. Repair of osteochondral defects with adipose stem cells and a dual growth factor-releasing scaffold in rabbits. $J$ Biomed Mater Res B Appl Biomater. 2010;92(2):552-560.

89. Lerou PH, Daley GQ. Therapeutic potential of embryonic stem cells. Blood Rev. 2005;19(6):321-331.

90. Hwang NS, Varghese S, Elisseeff J. Derivation of chondrogenicallycommitted cells from human embryonic cells for cartilage tissue regeneration. PLoS One. 2008;3(6):e2498.

91. Hwang NS, Varghese S, Lee HJ, et al. In vivo commitment and functional tissue regeneration using human embryonic stem cell-derived mesenchymal cells. Proc Natl Acad Sci U S A. 2008;105(52):20641-20646.

92. Toh WS, Lee EH, Guo XM, et al. Cartilage repair using hyaluronan hydrogel-encapsulated human embryonic stem cell-derived chondrogenic cells. Biomaterials. 2010;31(27):6968-6980.

93. de Bari C, Dell'Accio F, Tylzanowski P, Luyten FP. Multipotent mesenchymal stem cells from adult human synovial membrane. Arthritis Rheum. 2001;44(8):1928-1942.

94. Archer CW, Dowthwaite GP, Francis-West P. Development of synovial joints. Birth Defects Res C Embryo Today. 2003;69(2):144-155.

95. Fan J, Varshney RR, Ren L, Cai D, Wang DA. Synovium-derived mesenchymal stem cells: a new cell source for musculoskeletal regeneration. Tissue Eng Part B Rev. 2009;15(1):75-86. 
96. Shirasawa S, Sekiya I, Sakaguchi Y, Yagishita K, Ichinose S, Muneta T. In vitro chondrogenesis of human synovium-derived mesenchymal stem cells: optimal condition and comparison with bone marrowderived cells. J Cell Biochem. 2006;97(1):84-97.

97. Sakaguchi Y, Sekiya I, Yagishita K, Muneta T. Comparison of human stem cells derived from various mesenchymal tissues: superiority of synovium as a cell source. Arthritis Rheum. 2005;52(8): 2521-2529.

98. Fan J, Gong Y, Ren L, Varshney RR, Cai D, Wang DA. In vitro engineered cartilage using synovium-derived mesenchymal stem cells with injectable gellan hydrogels. Acta Biomater. 2009;6(3):1178-1185.

99. Nishimura K, Solchaga LA, Caplan AI, Yoo JU, Goldberg VM, Johnstone B. Chondroprogenitor cells of synovial tissue. Arthritis Rheum. 1999;42(12):2631-2637.

100. Park Y, Sugimoto M, Watrin A, Chiquet M, Hunziker EB. BMP-2 induces the expression of chondrocyte-specific genes in bovine synovium-derived progenitor cells cultured in three-dimensional alginate hydrogel. Osteoarthritis Cartilage. 2005;13(6):527-536.

101. Kurth T, Hedbom E, Shintani N, et al. Chondrogenic potential of human synovial mesenchymal stem cells in alginate. Osteoarthritis Cartilage. 2007;15(10):1178-1189.

102. O'Driscoll SW, Fitzsimmons JS. The role of periosteum in cartilage repair. Clin Orthop Relat Res. 2001;391(Supp1):S190-S207.

103. Stevens MM, Qanadilo HF, Langer R, Prasad Shastri V. A rapidcuring alginate gel system: utility in periosteum-derived cartilage tissue engineering. Biomaterials. 2004;25(5):887-894.
104. Stevens MM, Marini RP, Martin I, Langer R, Prasad Shastri V. FGF-2 enhances TGF-beta1-induced periosteal chondrogenesis. JOrthop Res. 2004;22(5):1114-1119.

105. Arnsdorf EJ, Jones LM, Carter DR, Jacobs CR. The periosteum as a cellular source for functional tissue engineering. Tissue Eng Part A. 2009;15(9):2637-2642.

106. Runyan CM, Jones DC, Bove KE, Maercks RA, Simpson DS, Taylor JA. Porcine allograft mandible revitalization using autologous adipose-derived stem cells, bone morphogenetic protein-2, and periosteum. Plast Reconstr Surg. 2010;125(5):1372-1382.

107. Lim SM, Choi YS, Shin HC, Lee CW, Kim DI. Isolation of human periosteum-derived progenitor cells using immunophenotypes for chondrogenesis. Biotechnol Lett. 2005;27(9):607-611.

108. de Bari C, Dell'Accio F, Luyten FP. Human periosteum-derived cells maintain phenotypic stability and chondrogenic potential throughout expansion regardless of donor age. Arthritis Rheum. 2001;44(1): 85-95.

109. Hui JH, Li L, Teo YH, Ouyang HW, Lee EH. Comparative study of the ability of mesenchymal stem cells derived from bone marrow, periosteum, and adipose tissue in treatment of partial growth arrest in rabbit. Tissue Eng. 2005;11(5-6):904-912.

110. Ostrander RV, Goomer RS, Tontz WL, et al. Donor cell fate in tissue engineering for articular cartilage repair. Clin Orthop Relat Res. 2001;(389):228-237.
Orthopedic Research and Reviews

\section{Publish your work in this journal}

Orthopedic Research and Reviews is an international, peer-reviewed, open access journal that focuses on the patho-physiology of the musculoskeletal system, trauma, surgery and other corrective interventions to restore mobility and function. Advances in new technologies, materials, techniques and pharmacological agents are particularly welcome. The journal welcomes

\section{Dovepress}

original research, clinical studies, reviews \& evaluations, expert opinion and commentary, case reports and extended reports. The manuscript management system is completely online and includes a very quick and fair peer-review system, which is all easy to use. Visit http://www.dovepress. com/testimonials.php to read real quotes from published authors. 